www.jcmtjournal.com

Open Access

\title{
Systemic humoral responses of non- muscle-invasive bladder cancer during BCG treatment: less is more
}

\author{
Fernando M. Calais da Silva ${ }^{1}$, Paula A. Videiraa ${ }^{2,3,4}$, Dário Ligeiro ${ }^{5}$, Maria Guadalupe Cabral ${ }^{3}$, Richard Sylvester ${ }^{6}$, \\ Fernando E. Calais da Silva', Hélder Trindade ${ }^{5}$ \\ ${ }^{I}$ Grupo Português Génito-Urinário, Hospital São José, 1050-059 Lisboa, Portugal. \\ ${ }^{2}$ UCIBIO, Departamento Ciências da Vida, Faculdade de Ciências e Tecnologia, Universidade Nova de Lisboa, $2829-516$ Caparica, Portugal. \\ ${ }^{3}$ Centro de Estudos de Doenças Crónicas, CEDOC, NOVA Medical School/Faculdade de Ciências Médicas, Universidade Nova de Lisboa, 1169-056 \\ Lisbon, Portugal. \\ ${ }^{4} C D G \&$ Allies, Professionals and Patient Associations International Network (CDG \& Allies - PPAIN), Faculdade de Ciências e Tecnologia, \\ Universidade Nova de Lisboa, 2829-516 Caparica, Portugal. \\ ${ }^{5}$ Centro de Sangue e Transplantação de Lisboa, IPST, IP., 1749-005 Lisboa, Portugal. \\ ${ }^{6}$ EAU Guidelines Office, 241040 Brussels, Belgium.
}

Correspondence to: Dr. Paula A. Videira, UCIBIO, Departamento Ciências da Vida, Faculdade de Ciências e Tecnologia, Universidade Nova de Lisboa, 2829-516 Caparica, Portugal. E-mail: p.videira@fct.unl.pt; Dr. Fernando M. Calais da Silva, Grupo Português Génito-Urinário, Hospital São José, 1050-059 Lisboa, Portugal. E-mail: fernando.calais@gmail.com

How to cite this article: Calais da Silva FM, Videira PA, Ligeiro D, Cabral MG, Sylvester R, Calais da Silva FE, Trindade H. Systemic humoral responses of non-muscle-invasive bladder cancer during BCG treatment: less is more. J Cancer Metastasis Treat 2017;3:116-26.

\section{Article history:}

Received: 06-04-2017

Accepted: 23-05-2017

Published: 14-07-2017

\section{Key words:}

Bladder cancer,

Bacille Calmette-Guérin, immunomodulatory molecules, multivariate analysis

\begin{abstract}
\end{abstract}

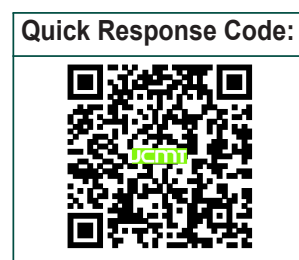




\section{INTRODUCTION}

Non-muscle-invasive bladder cancer (NMIBC) has an increasing incidence and a high relapse rate, even after transurethral resection of the bladder tumor (TURBT), the initial standard treatment. Due to the frequent need for follow-up procedures, NMIBC significantly reduces quality of life and is one of the most expensive malignancies to treat. Post-TURBT intravesical instillation of Bacille Calmette-Guérin (BCG), the attenuate strain of Mycobacterium bovis, is the recommended treatment for intermediate and highrisk $\mathrm{NMIBC},{ }^{[1]}$ by preventing relapse and progression of NMIBC -- stages Ta, T1 and carcinoma in situ. While partially successful, $30 \%$ to $50 \%$ of the patients do not respond and experience relapse within the first year of BCG treatment. Of these patients, 15\% develop tumor progression and form distant metastases. ${ }^{[2]}$

Despite many efforts, ${ }^{[3-5]}$ there are currently no biomarkers that can predict patient's prognosis and that discriminate those who will respond to BCG treatment from those who would be best served by more aggressive therapy such as cystectomy or, alternatively, radio- and chemotherapy. BCG instillations can cause side effects ranging from incommodious cystitis to sepsis and even death of patients in rare cases. This fact reinforces the need for selecting and accompanying patients who enroll in BCG immunotherapy.

Treatment with BCG was first used empirically by Morales in 1976. ${ }^{[6]}$ Today, it is well assumed that the efficacy of BCG is based on a massive, complex, and ongoing local immune activation. Hence, a healthy host immune system is a prerequisite to successful BCG therapy. ${ }^{[1,7,8]}$ Within bladder tissue, the leukocyte distribution before and after BCG therapy is remarkably different, and the induction of complex inflammatory cascade events, reflecting activation of multiple types of immune cells, is well known. ${ }^{[9,10]}$ The cascade of events results in secretion of an array of cytokines, chemokines, and cytotoxicity mediators that can be detected in tissue and in urine. ${ }^{[7,11]}$ These are summarized in Table 1. Examples are (1) pro-inflammatory, $\mathrm{T}$ helper type 1 (Th1) cytokines such as interleukin (IL)-1 $\beta$, IL-2, IL6 , tumor necrosis factor (TNF)- $\alpha$, interferon (IFN)- $\gamma$; (2) Th2 cytokines IL-4 and IL-10; (3) chemokines, as CCL2, CCL8, CCL3, IFN-y-inducible protein (IP-10), CXCL9; (4) cytotoxicity mediators, such as nitric oxide (NO) released by macrophages, and mediators of cytotoxic response such as perforin (Perf), granulysin (GNLY), and Fas ligand (Fas-L) pathway released by cytolytic lymphocytes [natural killer (NK) and T cytotoxic cells], and cytotoxic T lymphocyte antigen-4 (CTLA4) expressed by activated/exhausted T cell; and (5) molecules involved in stress homeostatic events such as heme oxygenase 1 (HMOX-1). The tight balance of such mediators is critical for the efficacy of BCG immunotherapy. Despite this knowledge, the precise immune mechanism involved in BCG therapy is still not completely clarified. Assessing immune response is thus fundamental to an understanding of BCG-induced antitumor mechanism and its prognostic value.

Interestingly, in many bacterial infections, analysis of immunomodulators detected in peripheral blood cells is extremely relevant to following a patient's immune response. ${ }^{[12]}$ Blood is the predominant sample substrate for systemic analysis, and it allows depiction of the overall inflammation burden that accompanies infection.

Significant changes in the number and function of peripheral blood cells have been reported over the course of BCG therapy, such as the increase in BCG-activated killer (BAK) cells. ${ }^{\left[{ }^{[]}\right.}$Few attempts have been made to assess the relevance of the systemic cytokine profile in peripheral blood cells. ${ }^{[13,14]}$ However, the expression of cytokines and other BCGinduced mediators that are systemically detected over the course of BCG instillation has never been properly addressed. In this work, we sought to profile the expression of key molecules expressed by blood cells of NMIBC patients during BCG treatment. We analyzed the expression of cytokines TNF- $\alpha$; IL10; IFN- $\gamma$, IL-1 $\beta$, IL-2, IL-4 and IL-6; chemokines CCL2, CCL3, CCL8, CXCL9 and IP-10; mediators of cytotoxic response CTLA4, Fas-L, Perf, GNLY and NOS2A; and HMOX-1, which is involved in homeostatic events. We established predictive cut-off values and developed a predictive grouping system that allows us to identify the most likely patients to relapse after BCG treatment.

\section{METHODS}

\section{Patients}

From July 2005 until July 2007, 58 patients [mean age of 67.8 years (range 45 to 82)] were assisted at the Hospital São José, Lisbon, Portugal and diagnosed with NMIBC. Patients were BCG naïve and with high-risk tumors (T1 tumor, G3** $[\mathrm{HG}]$ tumor), CIS, multiple and recurrent and large $(>3 \mathrm{~cm}) \mathrm{Ta}, \mathrm{G} 1 \mathrm{G} 2$ tumors, and they were treated with the same dose of BCG instillations (TICE ${ }^{\circledR}$ BCG) after TURBT. They entered this study after informed consent. BCG instillations were repeated once a week for 6 weeks 


\section{Table 1: List of molecules analyzed in this study}

\begin{tabular}{|c|c|c|}
\hline Name & Function & $\begin{array}{l}\text { Expression in bladder cancer } \\
\text { (methods) }\end{array}$ \\
\hline IL-1 $\beta$ & $\begin{array}{l}\text { Important mediator of inflammatory response, involved in a variety of cellular } \\
\text { activities, such as cell proliferation, differentiation, and apoptosis. Contributes } \\
\text { to inflammatory pain hypersensitivity }\end{array}$ & Tissue (immunochemistry) ${ }^{[31]}$ \\
\hline IL-2 & $\begin{array}{l}\text { Necessary for T cell growth and function. Stimulates the production of } \\
\text { IL-2 receptors on the surface of other immune effector cells, such as } \\
\text { macrophages and B cells as part of the immune response }\end{array}$ & $\begin{array}{l}\text { Present in urine during BCG } \\
\text { immunotherapy } y^{[32]} \\
\text { tissue (immunochemistry) } \\
\text { [i1] }^{[1]}\end{array}$ \\
\hline IL-4 & $\begin{array}{l}\text { Important role in regulating antibody production, hematopoiesis and } \\
\text { inflammation, and the development of effector T cell responses. Moreover, } \\
\text { promotes tumor development by increasing tumor cell resistance to apoptosis }\end{array}$ & $\begin{array}{l}\text { Tissue (immunochemistry) } \\
\text { bladder cancer cell lines }{ }^{[33]} \\
\text { reduced function-polymorphism is } \\
\text { associated with recurrence }{ }^{[7]}\end{array}$ \\
\hline IL-6 & $\begin{array}{l}\text { Involved in the acute phase response, T cell proliferation, B cell maturation, } \\
\text { macrophage maturation, and cytotoxic T-cell differentiation. Furthermore, } \\
\text { contributes to proliferation of cytotoxic NK cells and promotes the } \\
\text { differentiation of CD4 T cells into Th2 effector cells and it inhibits Th1 } \\
\text { differentiation }\end{array}$ & $\begin{array}{l}\text { Present in urine during } \mathrm{BCG} \\
\text { immunotherapy }{ }^{[32,34]} \\
\text { bladder cancer cell lines }\end{array}$ \\
\hline IL-10 & $\begin{array}{l}\text { Pleiotropic effects in immunoregulation and inflammation, down-regulates } \\
\text { the expression of Th1 cytokines, MHC class II presented antigens, and } \\
\text { costimulatory molecules on APCs. It enhances B cell survival, proliferation, } \\
\text { and antibody production }\end{array}$ & $\begin{array}{l}\text { inhibitory role in BCG-induced } \\
\text { macrophage cytotoxicity }{ }^{[36]}\end{array}$ \\
\hline IFN- $\gamma$ & $\begin{array}{l}\text { Critical in innate and adaptive immune responses, with immunostimulatory } \\
\text { and immunomodulatory effects, especially against viral and intracellular } \\
\text { bacteria and participates in tumor control. Promotes Th1 responses, namely } \\
\text { activating macrophages }\end{array}$ & Bladder cancer cell line $e^{[37]}$ \\
\hline TNF- $\alpha$ & $\begin{array}{l}\text { Involved in systemic inflammation and stimulates the acute phase reaction. } \\
\text { Regulation of immune cells. Endogenous pyrogen, able to induce fever, } \\
\text { apoptotic cell death, sepsis, cachexia, inflammation, and inhibit tumorigenesis } \\
\text { and viral replication }\end{array}$ & $\begin{array}{l}\text { Present in urine }{ }^{[32,38]} \\
\text { (immunochemistry) }^{[31]} \\
\text { bladder cancer cell line } e^{[37]} \\
\text { reduced function-polymorphism is } \\
\text { associated with recurrence }{ }^{[4]}\end{array}$ \\
\hline CCL2 & $\begin{array}{l}\text { Known as monocyte chemoattractant protein } 1 \text {. Displays chemotactic activity } \\
\text { for monocytes and basophils. Implicated in the pathogenesis of diseases } \\
\text { characterized by monocytic infiltrates, like psoriasis, rheumatoid arthritis, and } \\
\text { atherosclerosis }\end{array}$ & Tissue $(\mathrm{RT}-\mathrm{PCR})^{[7]}$ \\
\hline CCL3 & $\begin{array}{l}\text { Known as macrophage inflammatory protein } 1 \text { alpha plays a role in acute } \\
\text { inflammatory responses }\end{array}$ & Tissue $(\mathrm{RT}-\mathrm{PCR})^{[7]}$ \\
\hline CCL8 & $\begin{array}{l}\text { Known as monocyte chemoattractant protein } 2 \text {. Chemoattractant which } \\
\text { contributes to the local activation of many different immune cells, including } \\
\text { mast cells, eosinophils, basophils, monocytes, T cells, and NK cells involved } \\
\text { in the inflammatory response. Contribute to tumor-associated leukocyte } \\
\text { infiltration }\end{array}$ & Tissue $(\mathrm{RT}-\mathrm{PCR})^{[7]}$ \\
\hline IP-10 & $\begin{array}{l}\text { Chemokine CXCL10. Secreted by several cell types in response to IFN- } \gamma \text {. } \\
\text { Several roles, such as chemoattraction for monocytes/macrophages, T cells, } \\
\text { NK cells, and dendritic cells, promotion of T cell adhesion to endothelial } \\
\text { cells, antitumor activity, and inhibition of bone marrow colony formation and } \\
\text { angiogenesis }\end{array}$ & $\begin{array}{l}\text { Tissue }(\mathrm{RT}-\mathrm{PCR})^{[7]} \\
\text { bladder cancer cell line } e^{[37]}\end{array}$ \\
\hline CXCL9 & $\begin{array}{l}\text { Known as monokine induced by IFN- } \gamma \text { (MIG). T cell chemoattractant, which is } \\
\text { induced by IFN- } \gamma\end{array}$ & Tissue $(\mathrm{RT}-\mathrm{PCR})^{[7]}$ \\
\hline Fas-L & Key effector molecule in cell-mediated cytotoxicity & $\begin{array}{l}\text { BAK, LAK cells and PBCs stimulated } \\
\text { with BCG or IL-2 (FACS analysis) }{ }^{[28]}\end{array}$ \\
\hline GNLY & $\begin{array}{l}\text { Present in cytotoxic granules of cytotoxic T cells and natural killer cells, with } \\
\text { cytolytic and pro-inflammatory functions }\end{array}$ & \\
\hline Perf & Key effector molecule in cell-mediated cytotoxicity & $\begin{array}{l}\text { BAK, LAK cells, PBCs stimulated with } \\
\text { BCG or IL2 (FACS analysis) }{ }^{[28]}\end{array}$ \\
\hline NOS2A & $\begin{array}{l}\text { It is the nitric oxide synthase inducible by certain cytokines. The formed } \\
\text { product, nitric oxide, is a reactive free radical which acts as a biologic } \\
\text { mediator in several processes, including neurotransmission and antimicrobial } \\
\text { and antitumoral activities }\end{array}$ & Polymorphisms ${ }^{[39]}$ \\
\hline HMOX-1 & $\begin{array}{l}\text { Essential in heme catabolism. Highly expressed in various solid tumors, with } \\
\text { an important role in rapid tumor growth }\end{array}$ & NMIBC tissue specimens (RT-PCR) ${ }^{[27]}$ \\
\hline CTLA4 & $\begin{array}{l}\text { Expressed on the surface of helper and cytotoxic } T \text { cells and transmits an } \\
\text { inhibitory signal. Functions as an immune checkpoint, downregulating the } \\
\text { immune system }\end{array}$ & \\
\hline
\end{tabular}

BCG: Bacille Calmette-Guérin; RT-PCR: real time polymerase chain reaction; BAK: BCG-activated killer; LAK: lymphokine-activated killer; PBC: peripheral blood cells; FACS: fluorescence-activated cell sorting; NMIBC: non-muscle-invasive bladder cancer; IL: interleukin; IFN: interferon; TNF: tumor necrosis factor; IP-10: IFN- $\gamma$-inducible protein; Fas-L: Fas ligand; GNLY: granulysin; Perf: perforin; HMOX-1: heme oxygenase 1; CTLA4: cytotoxic T lymphocyte antigen-4 
followed by three weekly instillations at month 3,6 , 9 , and 12. All the patients were followed for one year and the outcome variables were: tumor progression, relapse, and disease-specific survival. Patients who showed no relapses within a year after the beginning of treatment were named "BCG responders" [40 patients ( 3 women/37 men, mean age of 68,3 years)]. Those patients who manifested relapses within that year were named "BCG-relapsing" [18 patients (1 woman/17 men, mean age of 67.5 years)]. In each case, four samples were collected before and after the first instillation and the week 6 instillation. The study has been approved by the ethical committee of the Hospital.

\section{Isolation of RNA and real-time PCR}

Blood specimens $(2.5 \mathrm{~mL})$ were collected in PAXgene ${ }^{\mathrm{TM}}$ tubes (Qiagen, Manchester, UK), incubated at room temperature for $4 \mathrm{~h}$ for RNA stabilization and then stored at $-80{ }^{\circ} \mathrm{C}$. RNA was extracted from whole blood using PAXgene ${ }^{\mathrm{TM}}$ Blood RNA System Kit (Qiagen), following manufacturer's instructions, and further purification of RNA was done with on-column DNase digestion. RNA concentrations and $A_{260}$-to- $A_{280}$ ratios were measured in a spectrophotometer, and only samples with $A_{260} / A_{280}$ ratios between 1.9 and 2.1 were further considered. $1 \mu \mathrm{g}$ of total RNA was reverse transcribed with random primers, using High Capacity cDNA Archive Kit (Applied Biosystems, Foster City, CA).

Real time PCR gene quantification analysis was performed as described, ${ }^{[7,15]}$ using Taqman assays from Applied Biosystems: Hs00234140_m1 (CCL2), Hs00234142_m1 (CCL3), Hs00271615_m1 (CCL8), Hs00171065_m1 (CXCL9), Hs00171042_m1 (IP-10), Hs00175480_m1 (CTLA4), Hs00181225_m1 (Fas-L), Hs01110250_m1 (HMOX-1), Hs00167257_m1 (NOS2A), Hs00169473 m1 (Perf), Hs00246266_m1 (GNLY), Hs00174128_m1(TNF- $\alpha) ; \mathrm{Hs} 00174086$ m1 (IL-10); Hs00174143_m1 (IFN- $\gamma), H s 00174097$ m1 (IL-1ß), Hs00174114_m1 (IL-2), Hs00174122_m1 (IL4), Hs00174131_m1 (IL-6), and 4352935E ( $\beta$-actin). Each reaction was performed in duplicate. All genes, including endogenous controls, were always analyzed in the same run to exclude between-run variations. The number of PCR cycles needed to reach fluorescence threshold in each sample was defined as the cycle threshold (Ct). The mRNA expression was normalized using $\beta$-actin gene expression as a reference according to our previous observations. ${ }^{[15]}$ Relative mRNA levels were calculated using formula $2^{-\Delta C t} \times 1,000$ which infers the number of mRNA molecules of the gene of interest per 1000 molecules of endogenous control. $\Delta \mathrm{Ct}$ stands for the difference between cycle threshold
(Ct) of the amplification curve of target gene and that of endogenous controls. Reactions with a Ct value higher than 35 cycles were considered negligible and were not considered further. Efficiency of the amplification reaction for each primer-probe was above 95\% (as determined by manufacturer).

\section{Statistical analysis}

The Kruskal Wallis test was used to compare ratios in patients with and without recurrence. Fisher's exact test was used to identify the factors that were significant in the univariate analysis. Multivariate logistic regression was used to identify the two factors that were retained in the multivariate analysis. A significance level of $P=0.05$ was used to identify possible factors for predicting response to BCG therapy in the univariate analyses. No correction was made for multiple endpoints or testing.

\section{RESULTS}

\section{BCG treatment induces significant systemic fast changes}

To assess whether BCG treatment induced significant changes in the expression of specific cytokines and molecular effectors in peripheral blood cells, we analyzed its expression in blood samples from patients during BCG therapy. The selected cytokines and molecular effectors depicted in Table 1 represent the reported complex events known to locally accompany BCG treatment, i.e. to occur in the bladder. Blood samples were collected before and $24 \mathrm{~h}$ after BCG treatment to assess fast changes. To assess prolonged changes, samples were collected at the first instillation (week 1) and at week 6 of BCG treatment. Significant levels of mRNA were obtained from all blood samples. Before BCG treatment (pre-BCG stage), the lowest expression levels were observed for IL-4 (0.024\% mRNA) and maximum for GNLY (252.38\% mRNA) [Figure 1]. During BCG treatment, we observed significant fast changes ( $24 \mathrm{~h}$ after the first treatment or after the instillation performed at 6th week) in $I L$ $1 \beta, T N F-\alpha, I L-10, G N L Y$, and Perf [Figure 2]. No significant prolonged changes, i.e. during treatment, were observed [Figure 2]. In fact, $24 \mathrm{~h}$ after the first BCG instillation, significant expression changes were observed. IL-1 $\beta$ mRNA increased from $12.94 \%$ before treatment to $16.48 \%$ after treatment $(P=0.033)$, TNF- $\alpha$ mRNA increased from $3.70 \%$ to $4.23 \%$ o $(P=$ 0.002 ), and $I L-10 \mathrm{mRNA}$ increased from $0.17 \%$ to $0.24 \%$ o $(P=0.026)$ [Figure 2]. At week 6 , changes were still observed and were sometimes more pronounced [Figure 2]. In fact, $I L-1 \beta$ mRNA increased from $11.46 \%$ to $20.76 \%$ o $(P=0.0001), T N F-\alpha$ mRNA increased from $3.12 \%$ to $4.57 \%$ o $(P=0.0045)$, and $I L-10$ increased 


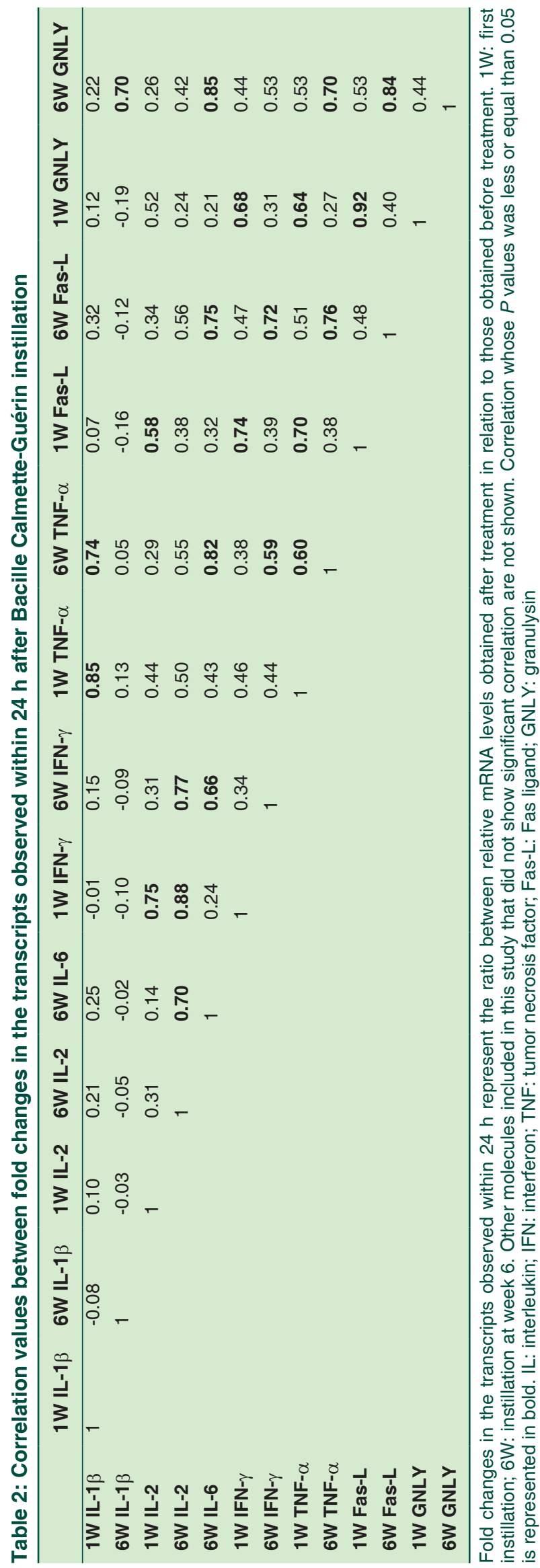

from $0.13 \%$ to $0.23 \%$ o $(P=0.0004)$. In addition, other significant changes were observed at week 6 of the treatment, such as decreased GNLY $(159.2 \%$ to $111.9 \%, P=0.008)$ and Perf (49.74\%o to $43.26 \%, P=$ $0.01)$ [Figure 2].

The observed fast changes in transcripts showed striking correlations [Table 2]. For example, there was positive correlation between pro-inflammatory cytokines: e.g. $I L-1 \beta$ correlated with TNF- $\alpha(P=0.85$ or 0.74 at 1 st or 6 th week treatment). There was also correlation between cytotoxic mediators: e.g. Fas-L correlated with GNLY $(P=0.92$ or 0.84 at 1 st or 6 th week treatment). Finally, correlation between proinflammatory cytokines and cytotoxic mediators was also observed: e.g. IL-1 $\beta$ and IL-6 correlated with GNLY cytotoxic mediator $(P=0.70$ and $P=0.85$, respectively). Overall, data suggested the involvement of pro-inflammatory and cytotoxic mechanisms in patient's response to BCG therapy.

\section{Systemic molecular changes differ between BCG responders and relapsing patients}

We then stratified our study population according to their response to BCG treatment. We considered two groups: patients who showed no relapses within a year after beginning treatment, i.e. "BCG responders" and patients who manifested relapses within that year, i.e. "BCG-relapsing." Stratification between BCG-responders and relapsing patients revealed interesting differences at week 6 . After treatment, BCG responders showed significantly less expression of IL-1 $\beta(18.54 \%$ o $)$ than relapsing patients $(25.61 \%$, $P=0.018$ ) [Figure 3]. At week 6 , before BCG treatment, there was significantly less expression in BCG responders of the following transcripts: IFN- $\gamma$ $(0.22 \% / 0.66 \%$ in responders $/$ relapsing, $P=0.04)$; HMOX-1 (10.80\% $/ 15.81 \%$ o, $P=0.006)$, and GNLY (165.78\%o/254.34\%o, $P=0.01$ ) [Figure 3]. Data suggest that the best response to BCG treatment involves the moderate contribution of specific immunomodulatory molecules.

\section{Multivariate analysis revealed cut-off values for BCG response}

To better discriminate BCG responders from relapsing patients, we used logistic regression analysis to establish cut-off values for each of the molecules identified above. We performed a univariate and a multivariate Cox analysis, whose results are represented in Table 3 . In the univariate analysis, the variables that better distinguished responder vs. relapsing patients were IL-1 $\beta$, IFN- $\gamma$, HMOX-1, and GNLY. Indeed, we could define a cut-off value for mRNA levels, below which it predicted a good BCG 
Table 3: Cut-off values of the relevant molecules with a predictive meaning for patients' response to BCG. Multivariate logistic regression was used to identify the two factors retained in the multivariate analysis

\begin{tabular}{llcc}
\hline & & Good factor & Prejudicial factor \\
\hline Univariate analysis & IL-1 $\beta$ at 6WAT & LE 12.5 & GT 12.5 \\
& IFN- $\gamma$ at 6WBT & LE 0.17 & GT 0.17 \\
& GNLY at 6WBT & LE 110.0 & GT 110.0 \\
Multivariate analysis & HMOX-1 at 6WBT & LE 13.0 & GT 13.0 \\
& GNLY at 6WBT & LE 110.0 & GT 110.0 \\
HMOX-1 at 6WBT & LE 13.0 & GT 13.0 \\
\hline
\end{tabular}

Values are relative mRNA molecules calculated by formula $2^{-\Delta \mathrm{Ct} *} 1,000$, which infers the number of mRNA molecules of each gene per 1,000 molecules of the endogenous control ( $\beta$-actin). The designation of "good factor" and "prejudical factor" is correlated with patients' response to BCG, namely no relapse or relapse in less than one year after treatment. BCG: Bacille Calmette-Guérin; 6WAT: sample collected $24 \mathrm{~h}$ after BCG instillation at week 6; 6WBT: sample collected before BCG instillation at week 6; LE: less than or equal to; GT: greater than

response $(\leq 12.5 \%$ o to IL- $1 \beta ; \leq 0.17 \%$ o to IFN- $\gamma, \leq 110 \%$ o to GNLY, and $\leq 13.0 \%$ to $\mathrm{HMOX}-1$ ).

In the multivariate analysis, only HMOX-1 and GNLY were shown to be independent predictive biomarkers. As shown in Table 3, we established a cut-off, above which these biomarkers are considered prejudicial factors. We then subdivided patients according to whether they show no prejudicial factors, one prejudicial factor, or two prejudicial factors (see supplementary data). One in twelve patients with no prejudicial factors relapsed (8.3\%). Four in twentythree patients showing one prejudicial factor relapsed $(17.4 \%)$ and finally, ten of fifteen patients showing two prejudicial factors relapsed (66.7\%). This allowed us to establish predictive cut-off values and a predictive grouping system, thus identifying the probability of relapse after BCG treatment.

\section{DISCUSSION}

Immunotherapies boost patient's immune response to improve its capacity to eliminate tumor. BCG is an immunotherapy, used as a standard of care to treat NMIBC patients to reduce cancer relapses. BCG instillations into the bladder attract antitumor effector immune cells to the tumor site, ${ }^{[8,9]}$ and three months after the BCG treatment course, the cellular infiltrate of $T$ and $B$ cells is concentrated in the persisting granulomas, focused on elimination of cancer cells. ${ }^{[16]}$ However, BCG treatment remains suboptimal because $30 \%$ to $50 \%$ of the patients show no response and/or relapse within the first year of treatment. ${ }^{[17]}$

Although the underlying mechanisms of BCG therapy are not fully elucidated, it is known that a Th1 response is required to stimulate cell-mediated tumoricidal activity. ${ }^{[18]}$ The level of the Th1 cytokine, IL-2, expressed

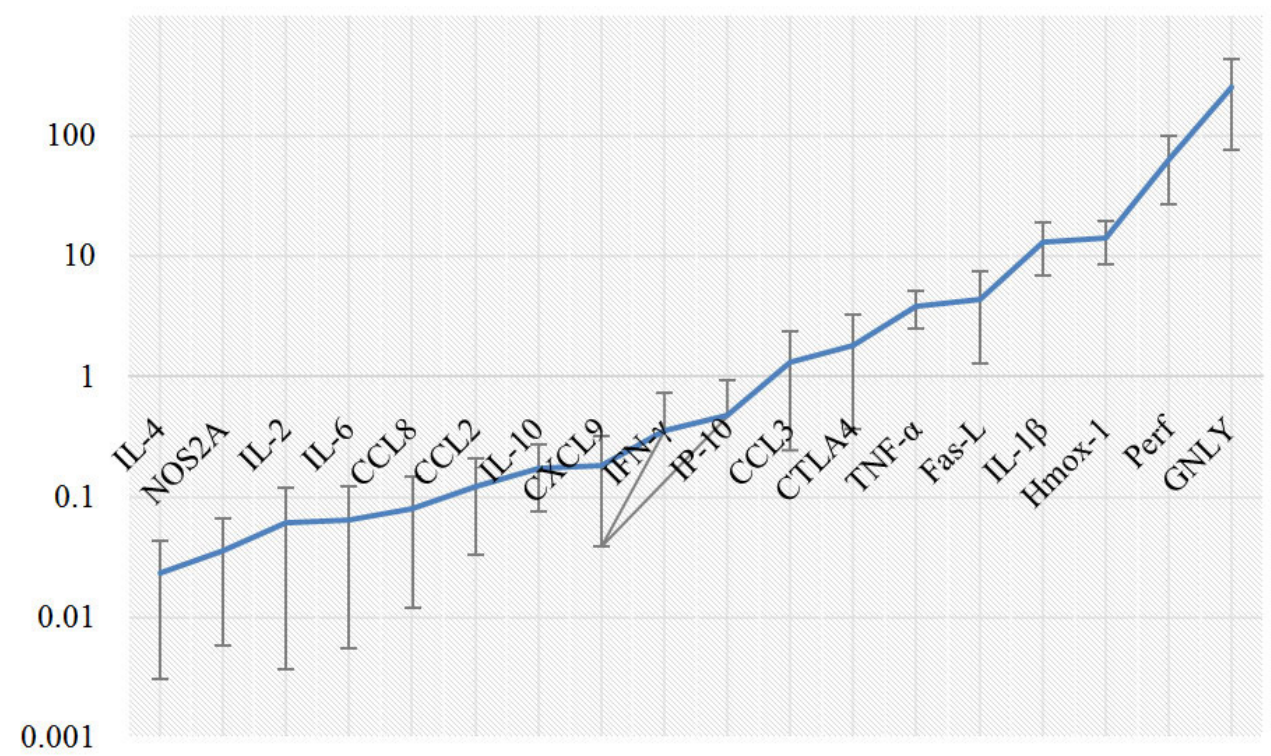

Figure 1: All the analyzed genes were significantly expressed at pre-BCG state, with the lowest mRNA levels observed for IL-4 and maximum for GNLY. Relative mRNA levels of IL-4, NOS2A, IL-2, IL-6, CCL8, CCL2, IL-10, CXCL9, IFN- $\gamma$, IP-10, CCL3, CTLA4, TNF- $\alpha$, Fas-L, IL-1 $\beta, H M O X-1$, Perf and GNLY were evaluated by real time PCR, as described in the Methods section. mRNA was obtained from blood samples of 58 patients, collected before any BCG treatment. Values were calculated, as referred to in the Methods section, by formula $2^{-\Delta C t}{ }^{*} 1,000$ and infers the number of mRNA molecules of a certain gene per 1,000 molecules of the endogenous control ( $\beta$-actin). BCG: Bacille Calmette-Guérin; PCR: polymerase chain reaction 
in situ can suggest patients at risk for bladder cancer relapses after a single course of BCG. ${ }^{[19]}$ Yet, despite efforts to analyze the immune response in bladder tissue before and after BCG therapy, ${ }^{[4,7-9]}$ there are currently no gold standard biomarkers to predict how effective or beneficial is the BCG-induced antitumor immune response. This knowledge is important to identify patients who may require more aggressive treatments such as cystectomy. ${ }^{[20]}$

A mode of predicting response to BCG therapy has
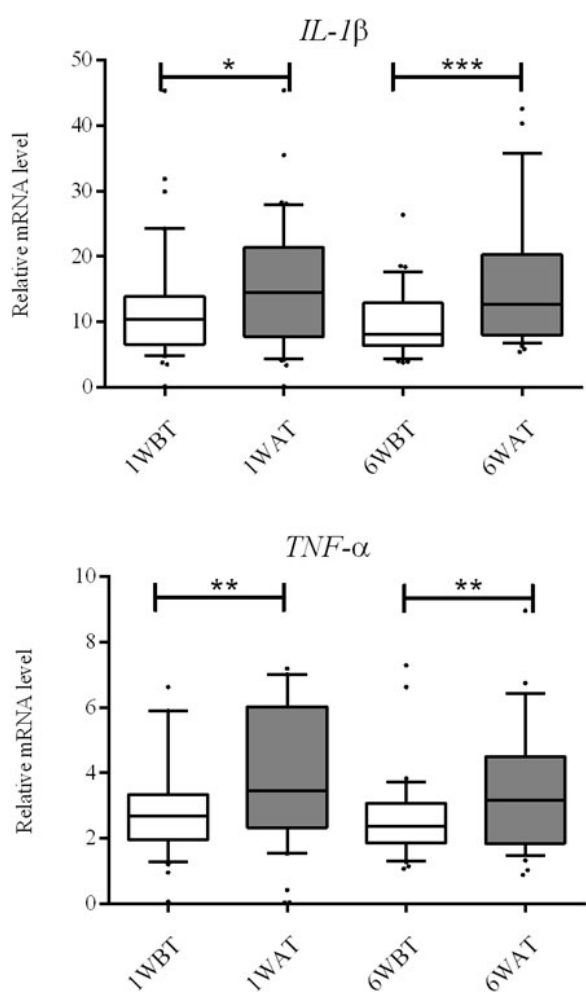

IL-10

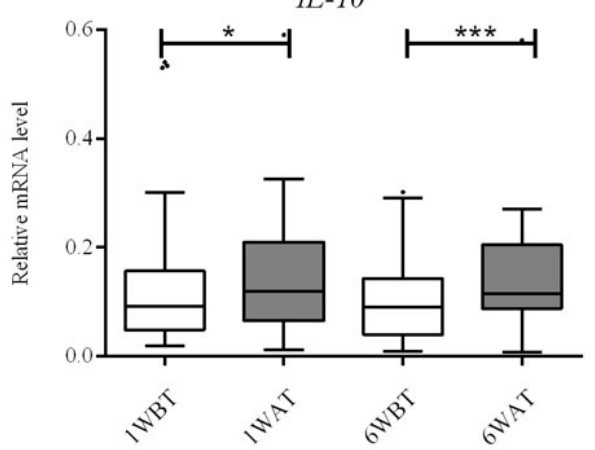

been suggested through the analysis of IL-2 and IFN- $\gamma$ mRNA in peripheral blood mononuclear cells during BCG treatment. IL-2 mRNA is increased in patients who responded with remission. ${ }^{[14]}$

In this study, we have extended this methodology and analyzed the profile of several key molecules expressed by blood cells in NMIBC patients treated with BCG. Expression was analyzed before and after (24 $\mathrm{h}$ interval) the 1st and the 6th week instillation, to assess fast (within $24 \mathrm{~h}$ ) and prolonged changes
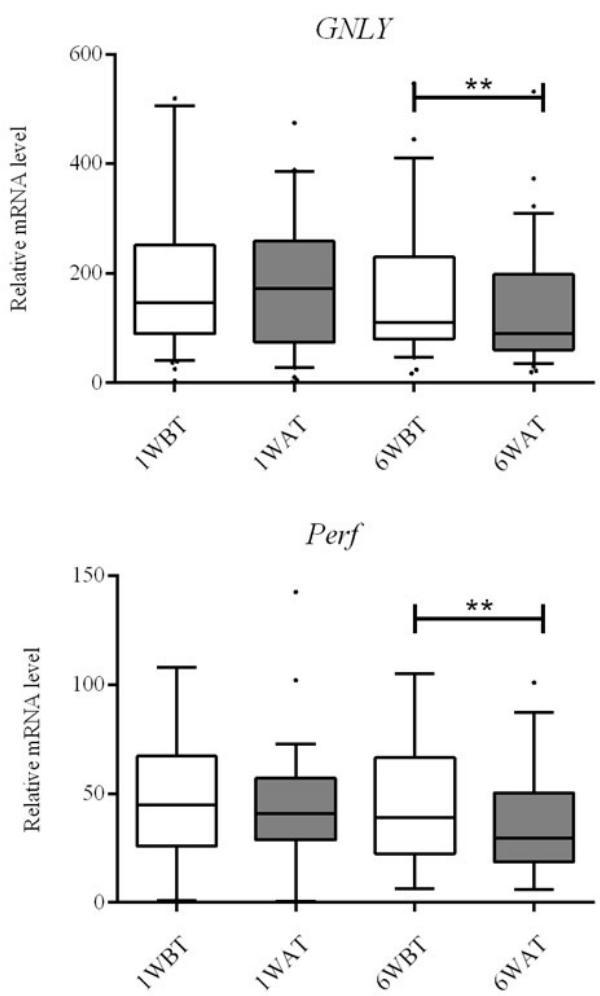

HMOX-1

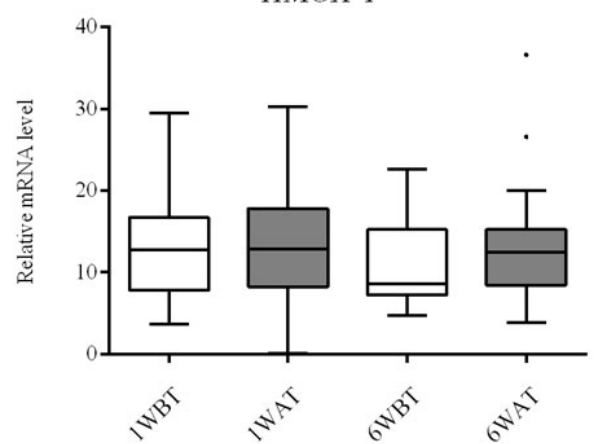

Figure 2: Expression of $I L-1 \beta, T N F-\alpha, I L-10, G N L Y$ and Perf genes was significantly altered in the study population after BCG instillation. The relative mRNA levels of $I L-1 \beta, T N F-\alpha, I L-10, G N L Y$, and Perf were evaluated by real time PCR, as described in the Methods section. mRNA was obtained from blood samples of 58 patients, collected before (1WBT) and $24 \mathrm{~h}$ after (1WAT) the BCG treatment performed 1 week after TURBT and/or before (6WBT) and $24 \mathrm{~h}$ after (6WAT) the BCG treatment performed 6 weeks after TURBT. Values were calculated by formula $2^{-\Delta \mathrm{Ct}}{ }^{*} 1,000$ and infer the number of mRNA molecules of a certain gene per 1,000 molecules of the endogenous control $\left(\beta\right.$-actin). Statistical significances $\left({ }^{\star} P<0.05,{ }^{*} P<0.001\right.$ and $\left.{ }^{* * *} P<0.0001\right)$ refer to the differences between samples collected before (1WBT or 6WBT) and $24 \mathrm{~h}$ after (1WAT or 6WAT) BCG instillation. When not labelled, no significant differences were identified. BCG: Bacille Calmette-Guérin; PCR: polymerase chain reaction; TURBT: transurethral resection of the bladder tumor 
during treatment.

During BCG treatment, significant fast changes were the expression of IL-1 $\beta$, TNF- $\alpha$ and IL-10, which increased at the 1st and 6th week, while the expression of GNLY and Perf decreased fast at 6th week. Correlations found between the fast changes of transcripts coding several pro-inflammatory cytokines and cytotoxic mediators further demonstrated that BCG promptly affects the systemic profile of mediators involved in both inflammatory and cytotoxic mechanisms. This coincides with previous studies demonstrating that BCG instillation influenced local immunological activity and a systemic immune response through both sorts of factors. ${ }^{\left[{ }^{[1]}\right.}$ For instance, a higher cytotoxic activity in the PBMCs after BCG instillation has been correlated to the appearance of IL-2 and IFN- $\gamma$ in the serum. ${ }^{[21]}$

Interestingly, our data showed that although the expression of IL-1 $\beta$ was higher after BCG instillation, there was a significantly lower expression of this potent pro-inflammatory cytokine in BCG-responders than in relapsing patients [Figure 3]. The increase in IL-1 $\beta$ is an expected, normal physiological inflammatory response to BCG treatment that boosts immune response in bladder tissue. However, it is well known that prolonged exposure to inflammatory cytokines has also the potential to stimulate tumor growth through the promotion of proliferation, angiogenesis, DNA damage (due to their capacity to generate reactive oxygen and nitrogen species), and other events favorable to metastasis. ${ }^{[22]}$ In fact, high levels of cytokines induce reactive oxygen and nitrogen species. ${ }^{[23]}$ This may explain why patients with an excessive elevation of systemic expression of IL-1 $\beta$ are more likely to relapse than patients who moderately express this cytokine.

In addition, it was observed that the basal expression profile of the immunomodulators also influences the response to BCG treatment. Indeed, patients who were considered BCG-responders, when compared with relapsing patients, exhibited significantly less expression of IFN- $\gamma$, HMOX-1 and GNLY immediately before the treatment at week 6 [Figure 3]. These data

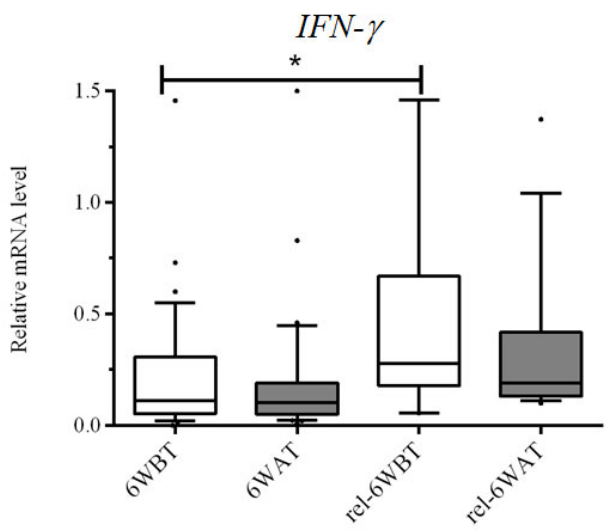

GNLY

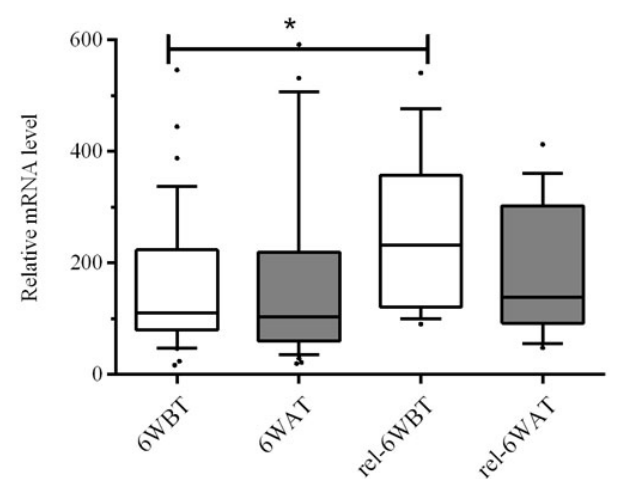

Figure 3: Expression of IL-1 $\beta$, IFN- $\gamma, H M O X-1$ and GNLY genes was significantly different between BCG responders and relapsing patients at week 6. Relative mRNA levels of IL-1 $\beta$, IFN- $\gamma, H M O X-1$, and GNLY were evaluated by real time PCR, as described in the Methods section. mRNA was obtained from blood samples of BCG responder and relapsing (rel-) patients, collected before (6WBT) and $24 \mathrm{~h}$ after (6WAT) BCG treatment performed 6 weeks after TURBT. Values were calculated by formula $2^{-\Delta C t} * 1,000$ and infer the number of mRNA molecules of a certain gene per 1,000 molecules of the average of the endogenous control $\left(\beta\right.$-actin). Statistical significances $\left.{ }^{\star} P<0.05\right)$ refer to differences between samples from BCG responders and relapsing patients collected before (6WBT) or 24 h after (6WAT) BCG 6 weeks treatment. BCG: Bacille Calmette-Guérin; PCR: polymerase chain reaction; TURBT: transurethral resection of the bladder tumor 
agree with the idea that specific immunomodulatory molecules are involved in the success of BCGtreatment, but in moderate levels. Patients with relapsing tumors may be genetically prone to develop exacerbated chronic inflammation or cytotoxic responses during BCG treatment or during the disease itself. ${ }^{[24]}$ This exacerbated inflammation may add to the burden of the disease. For instance, IFN- $\gamma$ is an essential component of cell-mediated immunity, and in BCG therapy it has an inhibitory effect on bladder cancer cells. ${ }^{[25]}$ However, depending on signalling intensity and microenvironmental factors, this cytokine can drive novel cellular and molecular inflammatory mechanisms that may underlie tumor initiation, immunoevasion, and progression. ${ }^{[26]}$ Likewise, HMOX-1 catalyzes the degradation of heme and is considered a key enzyme to protect cells from stress and to regulate cell growth and proliferation. However, increased levels of HMOX-1 expression and activity were observed in various tumor tissues. The knockdown of HMOX-1 suppresses the growth of bladder cancer cells, and HMOX-1 expression was even proposed as an independent predictor of NMIBC recurrence and progression. ${ }^{[27]}$ This agrees with our data, showing that patients with lower levels of HMOX1 before treatment are likely to respond better to BCG. On the other hand, granulysin is a cytolytic and pro-inflammatory molecule expressed by activated cytotoxic $\mathrm{T}$ cells and NK cells, ${ }^{[28]}$ necessary to kill target cancer cells. However, it has been described that granulysin kills bacteria ${ }^{[29]}$ and therefore it may lessen the efficacy of BCG therapy.

Our results point to the fact that the systemic expression of molecules that promote inflammation is involved in BCG host response. However, since inflammatory response shares various molecular targets and signaling pathways with the carcinogenic process, a good BCG response occurs only within limited levels of these molecules. Taking this into consideration, we define cut-off values for mRNA levels of IL-1 $\beta$, IFN- $\gamma$, HMOX-1, and GNLY, beneath which a good response to $B C G$ is predicted. This allowed us to discriminate $B C G$ responders from relapsing patients.

Univariate and multivariate analysis showed that IL$1 \beta$, IFN- $\gamma$, HMOX-1, and GNLY expression levels could reliably predict responder vs. relapsing patients. Based on our data, we established cut-off values above which these biomarkers are considered a prejudicial factor. We subdivided patients into whether they showed no prejudicial factors, one prejudicial factor, or two prejudicial factors (see supplementary data). We also established a predictive grouping system to identify the probability that patients would experience relapse after BCG treatment and to help design more personalized immune-based strategies. For instance, a promising avenue of clinical research in bladder cancer is the use of immune checkpoint inhibitors that target molecules involved in the balance and regulation of immune response, hence inducing proper T-cell anti-cancer response. ${ }^{[30]}$

In conclusion, the analysis of mRNA expression of PBMCs by real-time PCR was a relatively simple, accurate technique for assessing the expression profile of several key immunomodulators in patients with NMIBC, as compared with classical histopathological evaluations and even with urine detection because not all patients have urine detectable levels.

Our results revealed that molecules with immunomodulatory roles, such as IL-1 $\beta$, IFN- $\gamma$, HMOX-1, and GNLY, have a role in BCG therapy but only at certain amounts, above which they appear to contribute to poor response to treatment. Thus, we established a cut-off value for mRNA levels of each molecule and propose the use of this information to predict which patients with NMIBC will be good BCG-responders, which patients will relapse when undergoing BCG treatment, and who therefore would benefit from alternative treatment strategies.

\section{Authors' contributions}

Conceived and designed the study: H. Trindade, D. Ligeiro, F.M. Calais da Silva, F.E. Calais da Silva

Performed literature search and prepared manuscript: P.A. Videira, M.G. Cabral

Acquired clinical data: F.M. Calais da Silva, F.E. Calais da Silva

Performed the experimental study and data acquisition:

D. Ligeiro

Analyzed data and prepared presentation of manuscript: P.A. Videira

Performed statistical analysis: R. Sylvester

Revised the manuscript: F.M. Calais da Silva, P.A. Videira, D. Ligeiro, M.G. Cabral, R. Sylvester, F.E. Calais da Silva, $\mathrm{H}$. Trindade

\section{Acknowledgments}

We thank João Sobral, Helena Gouveia, and Sofia Mendes for help in preparing patients' samples and data.

\section{Financial support and sponsorship}

This work was supported by a grant of Astellas Pharma, obtained after application.

\section{Conflicts of interest}

There are no conflicts of interest. 


\section{Patient consent}

Patients entered this study after written informed consent and were analyzed anonymously.

\section{Ethics approval}

The study has been approved by the ethical committee of the Hospital. All procedures followed the universal bioethical principles (Universal Declaration on Bioethics and Human Rights of UNESCO, 19 October 2005; The Charter of Fundamental rights of the EU, 2000; Ethical principles for medical research involving human subjects - Declaration of Helsinki (2008) with 2013 amendments.

\section{REFERENCES}

1. Babjuk M, Oosterlinck W, Sylvester R, Kaasinen E, Böhle A, PalouRedorta J, Rouprêt M; European Association of Urology (EAU). EAU guidelines on non-muscle-invasive urothelial carcinoma of the bladder, the 2011 update. Eur Urol 2011;59:997-1008.

2. Tishler M, Shoenfeld Y. BCG immunotherapy -- from pathophysiology to clinical practice. Expert Opin Drug Saf 2006;5:225-9.

3. Lima L, Severino PF, Silva M, Miranda A, Tavares A, Pereira S, Fernandes E, Cruz R, Amaro T, Reis CA, Dall'Olio F, Amado F, Videira PA, Santos L, Ferreira JA. Response of high-risk of recurrence/ progression bladder tumours expressing sialyl-Tn and sialyl-6-T to BCG immunotherapy. Br J Cancer 2013;109:2106-14.

4. Lima L, Dinis-Ribeiro M, Longatto-Filho A, Santos L. Predictive biomarkers of bacillus calmette-guérin immunotherapy response in bladder cancer: where are we now? Adv Urol 2012;2012:232609.

5. Videira PA. Sweet side of bladder cancer. World J Clin Urol 2015;4:104-7.

6. Morales A, Eidinger D, Bruce AW. Intracavitary Bacillus CalmetteGuerin in the treatment of superficial bladder tumors. $J$ Urol 1976;116:180-3.

7. Videira PA, Calais FM, Correia M, Ligeiro D, Crespo HJ, Calais F, Trindade H. Efficacy of bacille Calmette-Guérin immunotherapy predicted by expression of antigen-presenting molecules and chemokines. Urology 2009; 74:944-50.

8. Böhle A. BCG's mechanism of action -- increasing our understanding. For the EBIN Group. Eur Urol 2000;37 Suppl 1:1-8.

9. Böhle A, Brandau S. Immune mechanisms in bacillus Calmette-Guerin immunotherapy for superficial bladder cancer. $J$ Urol 2003;170:964-9.

10. Alexandroff AB, Nicholson S, Patel PM, Jackson AM. Recent advances in bacillus Calmette-Guerin immunotherapy in bladder cancer. Immunotherapy 2010;2:551-60.

11. Luo Y, Knudson MJ. Mycobacterium bovis bacillus Calmette-Guerininduced macrophage cytotoxicity against bladder cancer cells. Clin Dev Immunol 2010;2010:357591.

12. Toossi Z, Hirsch CS, Wu M, Mayanja-Kizza H, Baseke J, Thiel B. Distinct cytokine and regulatory $\mathrm{T}$ cell profile at pleural sites of dual HIV/tuberculosis infection compared to that in the systemic circulation. Clin Exp Immunol 2011;163:333-8.

13. Agarwal A, Verma S, Burra U, Murthy NS, Mohanty NK, Saxena S. Flow cytometric analysis of Th1 and Th2 cytokines in PBMCs as a parameter of immunological dysfunction in patients of superficial transitional cell carcinoma of bladder. Cancer Immunol Immunother 2006;55:734-43.

14. Kaempfer R, Gerez L, Farbstein H, Madar L, Hirschman O, Nussinovich R, Shapiro A. Prediction of response to treatment in superficial bladder carcinoma through pattern of interleukin-2 gene expression. J Clin Oncol 1996;14:1778-86.

15. Videira PA, Ligeiro D, Correia M, Trindade H. Gene expression analysis in superficial bladder cancer: comparison of two suitable endogenous reference genes. Curr Urol 2007;1:145-50.

16. Fuge O, Vasdev N, Allchorne P, Green JS. Immunotherapy for bladder cancer. Res Rep Urol 2015;7:65-79.

17. Severino PF, Silva M, Carrascal MA, Calais F, Dall'Olio F, Videira PA. Bladder cancer -- glycosylation insights. Carbohydr Chem 2012;38:156-75.

18. Chen X, O'DONNELL MA, Luo Y. Dose-dependent synergy of Th1stimulating cytokines on bacille Calmette-Guerin-induced interferongamma production by human mononuclear cells. Clin Exp Immunol 2007;149:178-85.

19. Saint F, Patard JJ, Maille P, Soyeux P, Hoznek A, Salomon L, Abbou CC, Chopin DK. Prognostic value of a T helper 1 urinary cytokine response after intravesical bacillus Calmette-Guerin treatment for superficial bladder cancer. J Urol 2002;167:364-7.

20. Valentini CG, Bozzoli V, Larici AR, Larocca LM, Delogu G, Leone G, Pagano L. Systemic granulomatous reaction secondary to treatment of bladder cancer with bacillus calmette-guerin. Mediterr J Hematol Infect Dis 2012;4:e2012040.

21. Taniguchi K, Koga S, Nishikido M, Yamashita S, Sakuragi T, Kanetake H, Saito Y. Systemic immune response after intravesical instillation of bacille Calmette-Guérin (BCG) for superficial bladder cancer. Clin Exp Immunol 1999;115:131-5.

22. Coussens LM, Werb Z. Inflammation and cancer. Nature 2002;420:860-7.

23. Maeda H, Akaike T. Nitric oxide and oxygen radicals in infection, inflammation, and cancer. Biochemistry (Mosc) 1998;63:854-65.

24. Masson-Lecomte A, Rava M, Real FX, Hartmann A, Allory Y, Malats N. Inflammatory biomarkers and bladder cancer prognosis: a systematic review. Eur Urol 2014;66:1078-91.

25. Hawkyard SJ, Jackson AM, James K, Prescott S, Smyth JF, Chisholm GD. The inhibitory effects of interferon gamma on the growth of bladder cancer cells. J Urol 1992;147:1399-403.

26. Zaidi MR, Merlino G. The two faces of interferon- $\gamma$ in cancer. Clin Cancer Res 2011;17:6118-24.

27. Yim MS, Ha YS, Kim IY, Yun SJ, Choi YH, Kim WJ. HMOX1 is an important prognostic indicator of nonmuscle invasive bladder cancer recurrence and progression. J Urol 2011;185:701-5.

28. Brandau S, Suttmann H, Riemensberger J, Seitzer U, Arnold J, Durek C, Jocham D, Flad HD, Böhle A. Perforin-mediated lysis of tumor cells by Mycobacterium bovis Bacillus Calmette-Guérin-activated killer cells. Clin Cancer Res 2000;6:3729-38.

29. Ernst WA, Thoma-Uszynski S, Teitelbaum R, Ko C, Hanson DA, Clayberger C, Krensky AM, Leippe M, Bloom BR, Ganz T, Modlin RL. Granulysin, a T cell product, kills bacteria by altering membrane permeability. J Immunol 2000;165:7102-8.

30. Bidnur S, Savdie R, Black PC. Inhibiting immune checkpoints for the treatment of bladder cancer. Bladder Cancer 2016;2:15-25.

31. Sander B, Damm O, Gustafsson B, Andersson U, Håkansson L. Localization of IL-1, IL-2, IL-4, IL-8 and TNF in superficial bladder tumors treated with intravesical bacillus Calmette-Guerin. $J$ Urol 1996;156:536-41.

32. De Boer EC, De Jong WH, Steerenberg PA, Aarden LA, Tetteroo E, De Groot ER, Van der Meijden AP, Vegt PD, Debruyne FM, Ruitenberg EJ. Induction of urinary interleukin-1 (IL-1), IL-2, IL6 , and tumour necrosis factor during intravesical immunotherapy with bacillus Calmette-Guérin in superficial bladder cancer. Cancer Immunol Immunother 1992;34:306-12.

33. Conticello C, Pedini F, Zeuner A, Patti M, Zerilli M, Stassi G, Messina A, Peschle C, De Maria R. IL-4 protects tumor cells from anti-CD95 and chemotherapeutic agents via up-regulation of antiapoptotic 
proteins. J Immunol 2004;172:5467-77.

34. Bevers RF, Kurth KH, Schamhart DH. Role of urothelial cells in BCG immunotherapy for superficial bladder cancer. $\mathrm{Br} \mathrm{J}$ Cancer 2004;91:607-12.

35. Bevers RF, de Boer EC, Kurth KH, Schamhart DH. BCG-induced interleukin-6 upregulation and BCG internalization in well and poorly differentiated human bladder cancer cell lines. Eur Cytokine Netw 1998;9:181-6.

36. Luo Y, Han R, Evanoff DP, Chen X. Interleukin-10 inhibits Mycobacterium bovis bacillus Calmette-Guerin (BCG)-induced macrophage cytotoxicity against bladder cancer cells. Clin Exp Immunol 2010;160:359-68.
37. Yamada H, Odonnell MA, Matsumoto T, Luo Y. Interferon-gamma upregulates toll-like receptor 4 and cooperates with lipopolysaccharide to produce macrophage-derived chemokine and interferon-gamma inducible protein-10 in human bladder cancer cell line RT4. $J$ Urol 2005;174:1119-23.

38. Jackson AM, Alexandrov AB, Prescott S, James K. Production of urinary tumour necrosis factors and soluble tumour necrosis factor receptors in bladder cancer patients after bacillus Calmette-Guérin immunotherapy. Cancer Immunol Immunother 1995;40:119-24.

39. Ryk C, Steineck G, Wiklund NP, Nyberg T, de Verdier PJ. The (CCTTT) $\mathrm{n}$ microsatellite polymorphism in the nitric oxide synthase 2 gene may influence bladder cancer pathogenesis. J Urol 2010;184:2150-7. 